\title{
Clinical Evaluation of a Disposable Artificial Kidney
}

\author{
A. E. KULATILAKE,* M.B., F.R.C.S., F.R.C.S.ED. ; J. VICKERS, † B.SC. ; R. SHACKMAN, $\ddagger$ M.B., F.R.C.S.
}

\begin{abstract}
Summary : The in-vivo performance of a new disposable parallel flow countercurrent type of artificial kidney has been compared with that of the modified four-layered Kiil dialyser. The dialysance of urea and endogenous creatinine in the former was significantly better than in the latter for similar blood flow rates, and, moreover, unlike the dialysance with the Kiil dialyser it continued to improve over 12 hours. Among 100 disposable artificial kidneys tested no failure occurred from blood leaks despite the use of high negative pressures in the dialysate compartment. No pyrogen reactions were observed.
\end{abstract}

These new artificial kidneys were ready for use in less than one-seventh of the time taken to prepare the conventional Kiil dialyser. Other advantages are their low priming volumes, the lack of a pump in the blood line, and the reduced risk of infection.

\section{Introduction}

Regular intermittent haemodialysis as a definitive therapeutic procedure in the management of terminal renal disease is now widely practised. With this treatment patients maintain a steady state of health and can be adequately rehabilitated.

Since the first clinically successful haemodialysis (Kolff and Berk, 1943, 1944) there have been many advances in other fields of technology, and some of these have been usefully applied in developing more efficient artificial kidneys, but it was the availability of mass-produced, prepacked, presterilized disposable twin-coil dialysers (Kolff and Watschinger, 1956) that really made haemodialysis simple practically and led to the development of many dialysis units in the world.

For efficient intermittent haemodialysis the artificial kidney should have a low priming volume and preferably should be able to be operated without a blood pump. The countercurrent dialyser developed by Kiil (1960) and its subsequent modification (Cole et al., 1962, 1963) fulfilled these requirements. Indeed, about 700 of these machines (K.D.) were being used for intermittent haemodialysis in the United Kingdom in 1968. These dialysers, however, take a considerable time to prepare and need trained staff, not always readily available, to dismantle, clean, reassemble, and test each machine.

A disposable prepacked, presterilized countercurrent artificial kidney (D.D.) clearly has several advantages, and this is why we feel justified in presenting the results of our experience at Hammersmith in the use of such a machine.

\section{Materials and Methods}

The D.D. has a dialysis area of 1 square metre of cuprophane PT 300 arranged in 11 compartments. It weighs $5 \mathrm{~kg}$. and measures 58 by 17 by $12 \mathrm{~cm}$. (Figs. 1 and 2). ${ }^{1}$ The resistance to blood flow is $10 \mathrm{mg}$. $\mathrm{Hg}$ when the blood flow is $200 \mathrm{ml} . / \mathrm{min}$., the dialysate flow $1,000 \mathrm{ml} . / \mathrm{min}$., and the negative pressure $100 \mathrm{~mm}$. Hg. The modified Kiil dialyser ${ }^{2}$ has been used in

\footnotetext{
* Senior Registrar and Tutor in Surgery.

+ Senior Biochemist.

$¥$ Professor of Urology.

Urological Unit, Department of Surgery, Royal Postoraduate Medical School and Hammersmith Hospital, London W.12.
}

the management of the patients on our dialysis programme for the past five years. It has a surface area $0.98 \mathrm{sq} . \mathrm{m}$. and consists of cuprophane PT 150 arranged in four layers and is rebuilt for use at each dialysis. It weighs $35.5 \mathrm{~kg}$. and measures 98 by 38 by $19 \mathrm{~cm}$. (Fig. 2). The resistance to blood flow is variable.

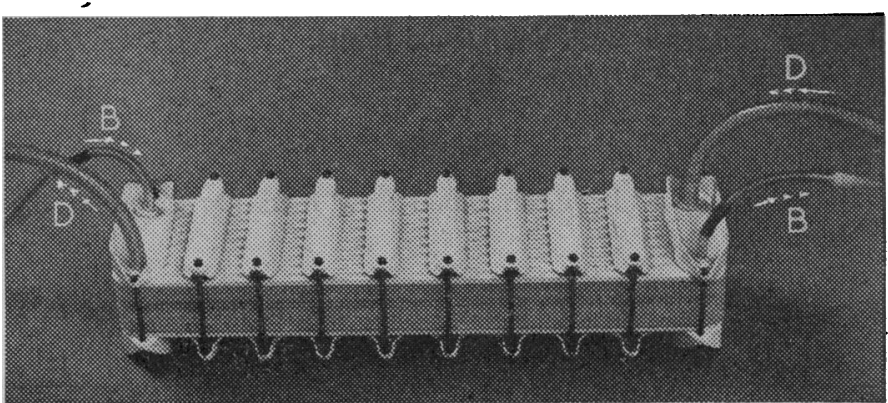

FrG. 1.-Disposable dialyser. $\mathrm{D}=$ Dialysis fluid. $\mathrm{B}=\mathrm{Blood}$; arrow indicates direction of flow. The whole machine is disposable.

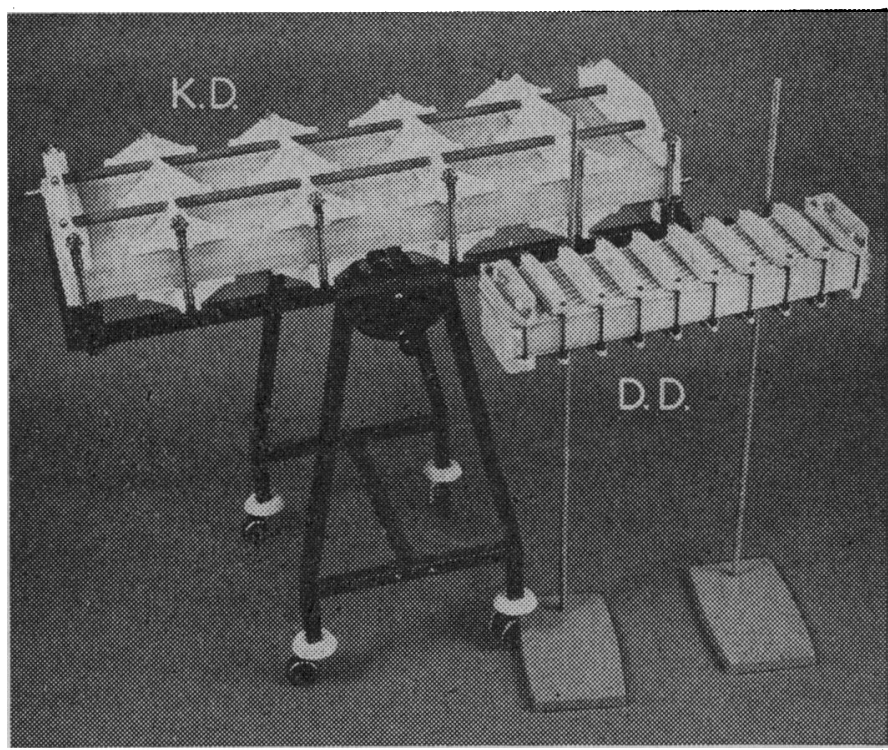

FIG. 2.-Comparison of sizes. K.D.=Kiil dialyser. D.D.=Disposable dialyser.

Eleven patients who were in a steady state in respect of serum electrolytes, urea, and blood pressure and had been on intermittent haemodialysis for at least three months (twiceweekly dialysis each of 12 hours by four-layered Kiil machine) were treated by disposable dialysers alternately. Single-pass dialysate fluid $(500 \mathrm{ml} . / \mathrm{min}$.) was delivered by an automatic proportionating and monitoring system ${ }^{3}$ at $38^{\circ} \mathrm{C}$. Arterial and venous blood and dialysate samples were taken hourly and the patients weighed hourly. Blood flow rates through the machine were measured by a timed bubble method (Sampson et al., 1969). A Technicon AutoAnalyzer was used for urea and creatinine estimations and their dialysance (clearances) were calculated from the formula of Wolf et al. (1951). The

\footnotetext{
1 Developed by Ab Gambro, Lund, Sweden.

2 Manufactured by Heppel Engineering, Harlow, Essex, U.K

- Manufactured by Lucas Ltd., Birmingham, England.
} 
loss of weight was determined from the results of 55 dialyses with the D.D. (including the present 11) according to the method of Papadimitriou and Kulatilake (1969).

$$
\text { Dialysance }(\mathrm{ml} . / \mathrm{min} .)=\frac{\mathrm{F}(\mathrm{Ca}-\mathrm{Cv})}{\mathrm{Ca}-\mathrm{Cb}}
$$

where $\mathrm{F}=$ blood flow rate in $\mathrm{ml} . / \mathrm{min}$., $\mathrm{Ca}=$ arterial concentration in $\mathrm{mg} . / 100 \mathrm{ml}$., $\mathrm{Cv}=$ venous concentration in $\mathrm{mg} . / 100 \mathrm{ml}$., and $\mathrm{Cb}=$ dialysate concentration in $\mathrm{mg} . / 100 \mathrm{ml}$.

The mean dialysance at a given hour was the mean of all the values from all the patients.

In the calculations of the relationship between creatinine dialysance (C.C.) and blood flow (B.F.) the method of least mean squares was used to obtain the straight line, passing through the origin, which best fits the data. The statistical variations were too large to justify any attempt to fit a curved line to the data. The equation of the line is given for each machine, together with confidence limits.

\section{Results}

Blood Flow.-The mean blood flow rates are given in the Table.

Two-hourly Mean Blood Flow Rates (ml./min.) in the K.D. and D.D.

\begin{tabular}{|c|c|c|c|c|c|c|c|}
\hline \multicolumn{2}{|c|}{ Hours of dialysis } & 2 & 4 & 6 & 8 & 10 & 12 \\
\hline $\begin{array}{l}\text { K.D. } \\
\text { D.D. }\end{array}$ & 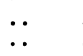 & $\begin{array}{l}95 \cdot 2 \\
71 \cdot 4\end{array}$ & $\begin{array}{l}120 \cdot 5 \\
101 \cdot 2\end{array}$ & $\begin{array}{r}95 \cdot 2 \\
113 \cdot 2\end{array}$ & $\begin{array}{r}97 \cdot 8 \\
100 \cdot 7\end{array}$ & $\begin{array}{l}87 \cdot 0 \\
98 \cdot 9\end{array}$ & $\begin{array}{r}84 \cdot 5 \\
102 \cdot 0\end{array}$ \\
\hline
\end{tabular}

Creatinine Dialysance v. Blood Flow.-For blood flow rates less than $150 \mathrm{ml} . / \mathrm{min}$. the dialysance of creatinine by the D.D. was significantly greater than that observed in the K.D. At a blood flow rate of $125 \mathrm{ml} . / \mathrm{min}$. the dialysance of creatinine through the D.D. was about $70 \mathrm{ml} . / \mathrm{min}$. (Fig. 3), whereas the corresponding value for the K.D. was 60 (Fig. 4). From these data it appears that the K.D. in use has reached its limits of dialysance at a blood flow rate of about $150 \mathrm{ml}$./ min.

Creatinine Dialysance v. Duration of Dialysis (Fig. 5).--In the second hour of dialysis the mean creatinine dialysance in the D.D. was $38 \mathrm{ml} . / \mathrm{min}$., in the K.D. it was $45 \mathrm{ml} . / \mathrm{min}$., but by the fourth hour the dialysance in the D.D. had increased to 66 and was virtually unchanged at 12 hours, whereas in the K.D. the comparable values were 45 and 39.

Urea Dialysance o. Duration of Dialysis (Fig. 6).-In the second hour of dialysis the mean urea dialysance in the D.D. was $49 \mathrm{ml}$./min. and in the K.D. it was $57 \mathrm{ml} . / \mathrm{min}$., but by the fourth hour the dialysance in the D.D. had increased to 82 , whereas in the K.D. the increase was less and the value did not exceed 62. At 12 hours the discrepancy was even more striking, for the dialysance in the D.D. was 79 while in the K.D. it was only 45.

Weight Loss and Dialysate Pressure (Fig. 7).- In the D.D. with dialysate negative pressures of 40 and $140 \mathrm{~mm}$. $\mathrm{Hg}$ the weight losses were 150 and $325 \mathrm{~g}$./hour respectively, while the corresponding values for the same dialysate negative pressures in the K.D. were 160 and 396 (Papadimitriou and Kulatilake, 1969). The mean weight loss in the D.D. was $190 \mathrm{~g}$./hour for a mean negative pressure of $79 \mathrm{~mm}$. $\mathrm{Hg}$, while the respective values in the K.D. were 193 and 54 (Papadimitriou and Kulatilake, 1969).
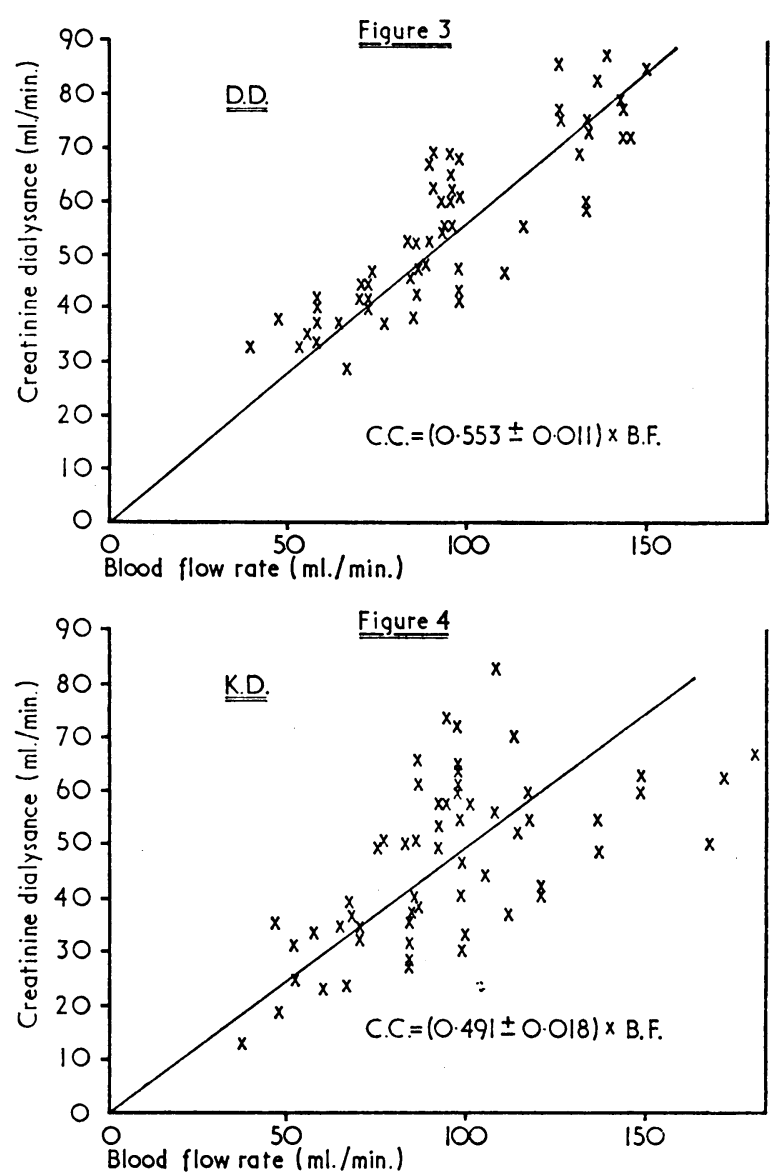

FIG. 3.-Relationship of creatinine dialysance to blood flow in FIG. 4.-Relationship of creatinine vivo). creatinine dialysance to blood flow in K.D. (in vivo)

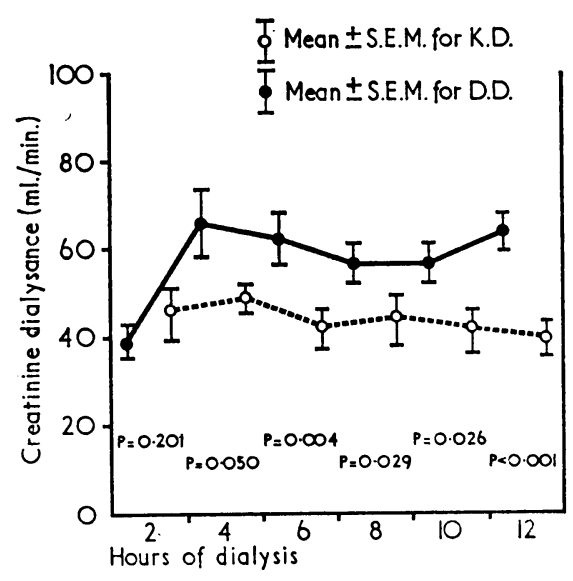

FIG. 5

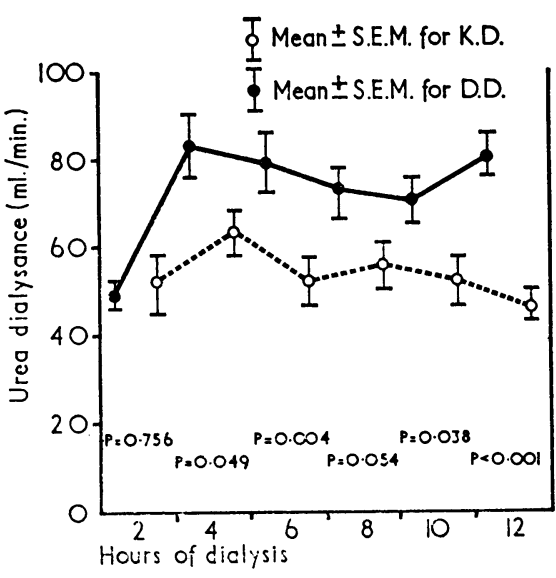

FIG. 6

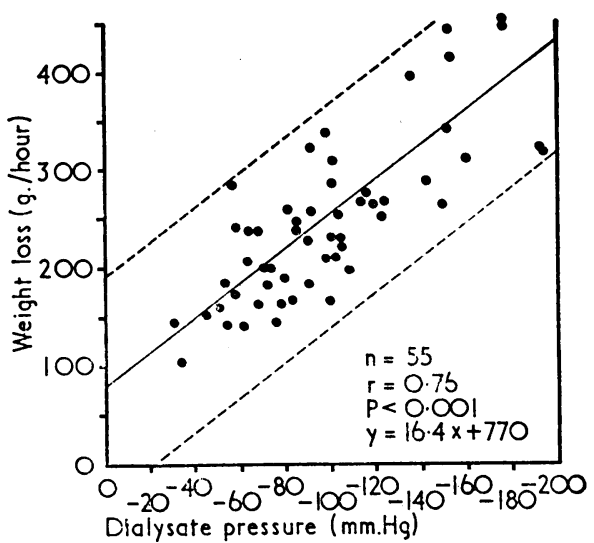

Fig. 7

Fig. 5.-Relationship of creatinine dialysance to duration of dialysis (in hours). Fig. 6.- Relationship of urea dialysance to duration of dialysis (in hours). FIG. 7.-Relationship of weight loss (g./hour) to dialysate negative pressure mm. Hg. Regression line and $95 \%$ confidence limits. 


\section{Discussion}

The disposable dialyser (D.D.) is more compact than the modified Kiil dialyser (K.D.) and is easily accommodated in a side room of a ward. This is a great advantage when very sick patients have to be dialysed, especially as a result of acute renal failure from trauma or major surgery. The creatinine dialysance is better in the D.D. than was seen in the K.D. (Figs. 3 and 4). This difference appears to be more pronounced with increasing blood flow through the dialysers. As no published data are available for in-vivo clearances under the conditions of these tests in the K.D. we have attempted to correlate the factors studied In the K.D. a wide scatter of the dialysance v. blood flow (Fig. 4) values is especially noted at blood flow rates around $100 \mathrm{ml} . / \mathrm{min}$. and higher. We feel that this is inevitable in an in-vivo system using hand-made dialysers for each dialysis. It is interesting to note that the scatter is less marked in the D.D. Even though it is well known that non-ideal dialysers (K.D. and D.D. fall into this category) have a curvilinear dialysance v. flow rate pattern we do not feel justified in assuming that this has occurred at the blood flow rates we have achieved. In fact, even in in-vitro studies of a four-layer K.D. the relationship appears to be linear (Freeman et al., 1964) at flow rates below $200 \mathrm{ml} . / \mathrm{min}$. We have not achieved flow rates more than $180 \mathrm{ml} . / \mathrm{min}$. Hence we believe that a statistically valid straight line can be drawn for these values, passing through the zero in the blood flow range studied.

The improvement in dialysance of creatinine and urea as dialysis progressed (Figs. 5 and 6 ) in the D.D. implied that the surface area of the membrane in the dialyser in contact with blood and dialysis fluid increased as the arterial blood flow improved, in the early stages from the relief of the venous spasm of the venous system of the shunt, and to the inevitable use in the D.D. of the higher negative pressures in the dialysate compartment, till the end of dialysis (see Table), as thicker dialysing membrane is used (PT 300). A rise in blood flow would have occurred in the K.D. if higher negative pressure was applied to the dialysate compartment, even though in practice this is unnecessary and could cause rupture of the dialysing membrane (PT 150), as it is thinner than that used in the D.D. The performance of the K.D., however, appeared to be better in the first two hours of dialysis than that of the D.D., but this increase was not statistically significant (Fig. 5).

A blood pump is usually needed in the D.D. if high blood flow rates are indicated-for example, the management of patients with acute renal failure and hypercatabolism-or if it is expedient to treat double the number of patients with chronic renal failure by halving the time at each dialysis (N. Alwall, personal communication, 1968). The D.D. has also been successfully used in the treatment of patients on long-term haemodialysis who had the subcutaneous arteriovenous fistula (Alwell, 1968).

Controlled fluid withdrawal from patients who gain weight between dialysis is desirable, and is easily achieved by applying negative pressure to the dialysate compartment. This can be done with confidence when the D.D. is used, because the dialysing membrane is thick (PT 300). We have not had any membrane leaks in 100 dialysers, and Alwall (1968) recorded none in more than 1,000 . If the conventional cuprophane (PT 150 ) is used in a K.D. membrane leaks can be quite a problem, hence PT 300 has been recommended (Berlyne and Crooks, 1965). In home dialysis a membrane rupture may cause a few hours' delay in starting the new dialysis once the K.D. is assembled; unlike in hospital, where prepared spare machines are usually available to cope with this emergency. It is our belief that this D.D. is eminently suitable as a standby, and this has been our practice at week-end dialysis.
The priming volume of blood is small. At a blood pressure of $20 \mathrm{~mm} . \mathrm{Hg}$ it is less than $250 \mathrm{ml}$. and the machine blood can be easily transfused back to the patient at the end of dialysis, thereby reducing unnecessary blood loss and decreasing the need, to a degree at least, for blood transfusion. The commonest complication in patients on regular intermittent haemodialysis is infection. It has been dealt with in detail in the Public Health Laboratory Services Working Party Report (1968) on infection in dialysis units. They claimed that disposable circuits would simplify the problems. In this system the contact between the patients' blood and staff is greatly reduced, as the whole machine and tubes are disposable. It was also interesting to note that we did not observe pyrogen reactions in the 100 dialyses we have so far performed with the D.D.

There is much to be said in favour of D.D. for use in the home dialysis apart from the advantage noted above. A prepacked sterile dialyser which is ready for use in 15 minutes, has a small priming volume, does not require a pump in the blood line, and is even smaller but more efficient than the K.D. must inevitably be attractive to a patient. The only problems concern disposal and its cost. Disposal is no problem in a hospital unit, because the incinerator has proved effective in our experience. For home dialysis the size of the machine would fit into a normal-size dustbin, but we have not discussed the matter with the local authorities. The cost, of course, depends on demand. We are informed, however, that if all the patients with renal failure requiring haemodialysis in the United Kingdom were treated by such machines-and we believe that a good case could be made for this-the price would compare favourably with the other types of disposable dialysers at present available.

It is even possible that it would be cheaper to use than the modified Kiil dialysers if the cost of staff time and blood were truly accounted.

Finally, we feel that this D.D. has many advantages to offer patients who need haemodialysis for short- or long-term renal replacemer.t.

We thank Sister J. Child and the nursing staff of the renal unit for their co-operation; the department of medical illustration for their help ; and $\mathrm{Ab}$ Gambro, Lund, Sweden, for the gift of disposable dialysers. We are indebted to Professor Nils Alwall for the personal communications, and to Mr. M. Holroyd for statistical advice.

\section{REFERENCBS}

Alwall, N. (1968). In Dialysis and Renal Transplantation: Proceedings of the 5th Conference of the European Dialysis and Transplant Association, edited by D. N. S. Kerr, p. 18. Amsterdam, Excerpta Medica.

Berlyne, G. M., and Crooks, L. G. (1965). In European Dialysis and Transplant Association: Proceedings of the 2 nd Conference on Renal Failure and Replacement of Renal Function, p. 285, odited by Public Health I poratory Service (1968). British 454.

Freeman, R. B., Setter, J. G., Maher, J. F., and Schreiner, G. E. (1964). Transactions. American Society for Artificial Intornal Organs, 10, 174.

Cole, J. J., Quinton, W. E., Williams, C., Murray, J. S., and Sherris, J. C. (1962). Transactions. American Society for Artificial Internal Organs, 8, 209.

Cole, J. J., Pollard, T. L., and Murray, J. S. (1963). Transactions. American Society for Artificial Internal Organs, 9, 67.

Kiil, F. (1960). Acta Chirurgica Scandinavica, Suppl. No. 253, p. 142.

Kolff, W. J., and Berk, H. Th. J. (1943). Geneeskundige Gids, 5, 21.

Kolff, W. J., and Berk, H. Th. J. (1944). Acta Medica Scandinavica, 117 121.

Kolff, W. J., and Watschinger, B. (1956). Fournal of Laboratory and Clinical Medicine, 47, 969.

Papadimitiou, M., and Kulatilake, A. E. (1969). Bio-Medical Engineering.

Sampson, D., Papadimitrious, M., and Kulatilake, A. E. (1969). In Wolf, A. V., Rem of Clinical Investigation, 30, 1062 . 